\title{
Avaliação de híbridos comerciais de milho para utilização como silagem na Região Sul do Brasil
}

\author{
Evaluation of commercial corn hybrids for silage use in the South Region of Brazil
}

\author{
Andréa Mittelmann ${ }^{1}$ Fausto de Souza Sobrinho ${ }^{2}$ Jackson Silva e Oliveira ${ }^{2}$ \\ Sandra Beatriz Vicenci Fernandes ${ }^{3}$ Carlos Alberto Lajús ${ }^{4}$ Mário Miranda ${ }^{4}$ \\ João Cláudio Zanatta ${ }^{5}$ José Luiz Moletta $^{6}$
}

\section{RESUMO}

As temperaturas baixas e geadas que ocorrem na Região Sul, durante a estação fria, determinam uma diminuição em quantidade e qualidade das pastagens. Para suprir as necessidades dos animais nos períodos de escassez de forragem, a silagem de milho tem sido muito utilizada. Tem sido apontada a existência de diferenças entre genótipos de milho quanto à produção e qualidade da silagem obtida. O objetivo deste trabalho foi identificar o potencial de híbridos comerciais de milho para produção de silagem na Região Sul do Brasil. Vinte e um híbridos foram testados em sete locais (Cascavel, Chapecó, Ijuí, Lages, Ponta Grossa, Teutônia e Urussanga), em delineamento de blocos casualizados com três repetições. Foram avaliados a produção de matéria seca $e$ o potencial de produção de leite, estimado com base em análises bromatológicas. Houve diferença significativa entre híbridos quanto aos caracteres avaliados. As médias dos híbridos variaram de 11,27 a 14,83t ha $a^{-1}$ para produção de matéria seca e de 4,868 a 7,207 $\mathrm{kg} \mathrm{ha}^{-1}$ para produção de leite. Os efeitos de local e da interação de híbrido por local também foram importantes na determinação dos caracteres. As médias dos locais para produção de matéria seca variaram de 8,69 a 19,22t ha-1 e para produção de leite de 3,845 a $8,515 \mathrm{~kg} \mathrm{ha}^{-1}$, tendo Cascavel apresentado os valores mais altos. Existe variabilidade entre os materiais indicados para cultivo na Região Sul do Brasil quanto ao potencial de utili- zação na forma de silagem. Entretanto, como a classificação dos híbridos é fortemente influenciada pela interação de genótipos por ambientes, é necessário que as recomendações sejam regionalizadas.

Palavras-chave: Zea mays, alimentação animal, matéria seca, leite.

\section{ABSTRACT}

Low temperatures and frosts that occur in the South Region of Brazil during the cool season determine a decrease in quality and amount of forage in pastures. To supply the animal nutrition requirements at this time, corn silage has been widely used. Differences among corn genotypes, regarding dry matter production and forage quality, have been found. The objective of this paper was to identify the commercial corn hybrids potential for silage production in the South Region of Brazil. Twenty-one hybrids were compared at seven dairy areas (Cascavel, Chapecó, Ijuí, Ponta Grossa, Teutônia and Urussanga), using a completely randomized block design with three replications. Dry matter production and an estimate based on bromatological analysis of the potential milk production were evaluated. There were significant differences among hybrids for the evaluated traits. Hybrids averages varied from 11.,27 to

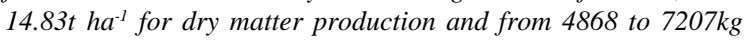
$h^{-1}$ for milk production. The effects of sites and hybrid by site interaction were important for the determination of both traits.

${ }^{1}$ Engenheiro Agrônomo, Doutor, Pesquisador da Embrapa Gado de Leite, CP 403, 96001-970, Pelotas, RS, Brasil. E-mail: andream@cnpgl.embrapa.br. Autor para correspondência.

${ }^{2}$ Engenheiros Agrônomos, Doutores, Pesquisadores da Embrapa Gado de Leite, Brasil.

${ }^{3}$ Engenheiro Agrônomo, MSc, Professor Adjunto, Unijuí, RS, Brasil.

${ }^{4}$ Engenheiro Agrônomo, MSc, Pesquisador da Empresa de Pesquisa Agropecuária e Extensão Rural de Santa Catarina S.A. (EPAGRI), Chapecó, SC, Brasil.

${ }^{5}$ Engenheiro Agrônomo, MSc, Pesquisador da EPAGRI, Lages, SC, Brasil.

${ }^{6}$ Zootecnista, MSc, Pesquisador do Instituto Agronômico do Paraná (IAPAR), Ponta Grossa, PR, Brasil. 
Sites' average for dry matter production varied from 8.69 to

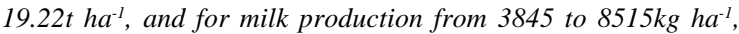
with Cascavel showing the highest values. There is variability among cultivars indicated for the South Region of Brazil considering the potential to be used as silage. However, because the hybrids ranking is strongly affected by genotype $x$ environment interaction, cultivars must be recommended for specific areas.

Key words: Zea mays, animal feeding, dry matter, milk.

\section{INTRODUÇÃO}

A região subtropical do Brasil apresenta ótimas condições para o desenvolvimento de sistemas de produção de leite eficientes e competitivos. As condições climáticas são favoráveis aos animais de raças especializadas e permitem o crescimento de espécies forrageiras de alta qualidade nutricional (GOMES et al., 2000). Esta região destaca-se por apresentar a segunda maior produção de leite e o terceiro maior rebanho de vacas leiteiras, além de produtividade acima da média nacional (YAMAGUCHI et al., 2002). Em 2001, a Região Sul produziu 5,2 milhões de litros de leite, cerca de $25 \%$ da produção brasileira (YAMAGUCHI et al., 2002).

Para a pecuária leiteira, há necessidade, durante todo o ano, de alimento em quantidade e qualidade capazes de suprir as necessidades nutricionais elevadas, especialmente da categoria de vacas em lactação. Na estação fria, as temperaturas baixas e as geadas que ocorrem na Região Sul determinam uma diminuição em quantidade e qualidade das pastagens. Um estudo sobre a produção de leite no Rio Grande do Sul aponta como maior fator de estrangulamento a falta de reserva alimentar, que é mais crítica nos meses de março, abril e novembro (BITENCOURT et al., 2000). A produção e utilização de forragens conservadas nos sistemas de produção de leite tem como principais objetivos: elevar e estabilizar a disponibilidade de forragem; complementar e/ou substituir dietas nos períodos de escassez; equilibrar as dietas e aumentar a carga animal (GOMES et al., 2000). Entre as opções de forrageiras para ensilagem, o milho se destaca por apresentar grande produtividade de matéria seca, bom valor nutritivo e boa digestibilidade (GOMES, 2002).

A escolha da cultivar de milho para produção de silagem deve incluir aspectos agronômicos da cultura e características bromatológicas e nutricionais (GOMES et al., 2000). Tem sido observada a existência de variabilidade entre híbridos tanto para produtividade de matéria seca como para qualidade (ALMEIDA FILHO, 1996; MELO et al., 1999; VILLELA, 2001; OLIVEIRA et al., 2003). Entretanto, essas características são também afetadas pelo ambiente e apresentam interação entre genótipo e ambiente. Portanto, existe necessidade de avaliação destes híbridos em diversos locais, representativos das principais áreas de produção de milho para silagem.

O objetivo do presente trabalho foi identificar o potencial de híbridos comerciais de milho para produção de silagem na Região Sul do Brasil.

\section{MATERIAL E MÉTODOS}

Foram testados 21 híbridos de milho recomendados para a Região Sul, sendo eles: BRS3150, HT14A, 97HT129 e HT40B (Embrapa); CD304, CD3121 e OC705 (Coodetec); DKB909, AG122 e AG5011 (Monsanto); AGN3050, AGN3100 e AGN3180 (Agromen); Tork e Traktor (Syngenta); SG6418 (Sementes Guerra); DAS766 (Dow Agroscience); AS1533 e AS3477 (Agroeste); P3041 e P3021 (Pioneer). Os ensaios foram conduzidos no ano agrícola de 2001/ 2002 em sete locais: Cascavel (PR), Chapecó (SC), Ijuí (RS), Lages (SC), Ponta Grossa (PR), Teutônia (RS) e Urussanga (SC).

A semeadura foi realizada nos dias 18/10 em Cascavel, 30/10 em Ponta Grossa, 8/11 em Lages, 13/11 em Chapecó, 23/11 em Ijuí, 30/11 em Urussanga e 31/12 em Teutônia. O delineamento utilizado foi em blocos casualizados, com três repetições. As parcelas foram constituídas por quatro linhas de oito metros de comprimento, espaçadas entre si de $0,8 \mathrm{~m}$. A população final após o desbaste foi correspondente a 54.000 plantas por hectare. Das três repetições de cada tratamento, uma foi sorteada para monitoramento do ponto de colheita. Desta forma, o tratamento foi colhido quando os grãos dessa parcela apresentavam-se no ponto de ensilagem (grãos farináceos). No momento da colheita, foram avaliados os seguintes caracteres: número de plantas (estande) e produção total de matéria verde.

Para determinação das características bromatológicas, foram amostradas cinco plantas de cada tratamento. O material foi picado e ensilado em um mini-silo de PVC. Após trinta dias, realizaram-se as seguintes determinações na silagem produzida: peso da amostra seca ao ar, peso de amostra seca a $105^{\circ} \mathrm{C}$, porcentagem de matéria seca, teor de proteína bruta, de fibra em detergente neutro e a digestibilidade in vitro da matéria seca. A determinação dessas características foi efetuada por meio de espectrofotometria no infravermelho próximo (NIRS), na Universidade de Passo Fundo, no Rio Grande do Sul. A produtividade de matéria seca foi estimada multiplicando-se o teor de matéria seca 
correspondente a cada tratamento pela produção de matéria verde.

A estimativa do potencial para produção de leite ( $\mathrm{kg} \mathrm{ha}^{-1}$ ) de cada cultivar de milho foi obtida empregando-se a metodologia MILK95 (UNDERSANDER et al., 1993). Para estas estimativas, são considerados dados de produtividade de matéria verde, porcentagem de matéria seca e teores de proteína bruta, fibra em detergente neutro e digestibilidade in vitro da matéria seca. Para emprego do método MILK95, consideraram-se vacas de $530 \mathrm{~kg}$, no terço médio da lactação, produzindo $24 \mathrm{~kg}$ de leite por dia, com 3,4\% de gordura e o uso, quando necessário, de milho e farelo de soja para atender às demandas de energia e proteína bruta. Consideraram-se também $12 \%$ de perdas no silo ou no cocho. O potencial de cada cultivar para produção de leite ( $\mathrm{kg} \mathrm{t}^{-1}$ de MS) foi combinado com a produtividade de matéria seca de cada parcela para se conhecer o potencial de produção de leite por área $\left(\mathrm{kg} \mathrm{ha}^{-1}\right)$.

Inicialmente foram realizadas análises de variância para os dados de estande, ou número de plantas por hectare, em todos os locais. Nos casos em que a fonte de variação tratamentos não foi significativa, procedeu-se a uma análise de covariância, utilizando o estande como co-variável, para a correção da produtividade de matéria seca, como proposto por RAMALHO et al. (2000).

Em cada local de avaliação, foram realizadas análises de variância individuais para as características produtividade de matéria seca de silagem $\left(\mathrm{tha}^{-1}\right)$ e potencial de produção de leite $\left(\mathrm{kg} \mathrm{ha}^{-1}\right)$. Posteriormente, foram realizadas análises conjuntas, segundo o modelo (Ramalho et al., 2000): Yijk = m + pi + ak + (pa)ik + rj(k) + eijk, em que Yijkéo valor observado na parcela experimental que recebeu o tratamento i, na repetição j, dentro do local k; m corresponde à média geral do experimento; pi é o efeito do tratamento $\mathrm{i}(\mathrm{i}=1,2,3, \ldots 21)$; ak é o efeito do local $\mathrm{k}(\mathrm{k}=1$, 2); (pa)ik é o efeito da interação do tratamento i com o local $\mathrm{k}$; rj(k) é o efeito da repetição $\mathrm{j}(\mathrm{j}=1,2)$, dentro do local $\mathrm{k}$ e eijk é corresponde ao erro experimental.

As médias de tratamentos foram comparadas pelo teste de SCOTT \& KNOTT (1974) a $5 \%$ de probabilidade. O programa utilizado foi o GENES (CRUZ, 2001)

Foram estimadas correlações de Spearman (STEEL \& TORRIE, 1980) baseadas na ordem de classificação dos genótipos, de cada local com a média geral.

\section{RESULTADOS E DISCUSSÃO}

Na análise conjunta, houve diferença significativa entre híbridos e entre ambientes. Além disso, houve significância do efeito da interação híbridos x locais, o que indica que os híbridos respondem de forma diferenciada a diferentes condições de ambiente (Tabela 1). A ocorrência de interação significativa dificulta a recomendação de cultivares, pois pode haver alteração na classificação dos híbridos de acordo com o local de cultivo. Esse resultado indica que a recomendação de cultivares para utilização como silagem na Região Sul do Brasil não pode ser generalizada.

Resultados semelhantes têm sido encontrados para outras regiões do País (OLIVEIRA et al., 2003). Realmente, a classificação dos híbridos, baseada na produtividade de matéria seca e no potencial de produção de leite da silagem, variou acentuadamente entre locais (dados não mostrados). As correlações de Spearman para produção de matéria seca entre cada um dos locais e a média geral variaram de 0,27 a 0,83 , sendo o ensaio de Ponta Grossa o melhor correlacionado com a classificação obtida para a média dos ambientes. Para produção de leite, essas correlações foram mais altas, variando de 0,51 a 0,85 .

As médias dos locais para produção de matéria seca variaram de 8,69 a 19,22t ha ${ }^{-1}$ e para produção de leite de 3845,25 a 8515,11 $\mathrm{kg} \mathrm{ha}^{-1}$, tendo Cascavel apresentado os valores mais altos para ambos os caracteres, seguido do ensaio realizado em Ponta Grossa. As menores médias foram obtidas em Ijuí (Tabelas 2 e 3). A amplitude observada foi maior do que a registrada para a Região Sudeste (OLIVEIRA et al., 2003), indicando grandes variações de ambiente. Além disso, algumas importantes bacias leiteiras, como as localizadas na metade sul do Estado do Rio Grande do Sul, com condições de clima e solo bastante diferenciadas, não foram representadas neste trabalho, podendo-se esperar diferenças ainda maiores no comportamento dos híbridos. A ocorrência de médias elevadas em Cascavel e Ponta Grossa e mais baixas em Ijuí, Teutônia e Urussanga concorda com os resultados obtidos para o ano agrícola de 2000/2001 (OLIVEIRA, 2001). Não foi detectada uma relação clara destas médias com fatores de tipo de solo, temperaturas e volume de precipitação.

Houve diferenças entre híbridos nas análises individuais, exceto para produtividade de matéria seca nos ensaios de Chapecó e Ijuí e potencial de produção de leite no ensaio de Ijuí (Tabela 1). Este resultado evidencia que existe variabilidade entre os híbridos comerciais de milho para o potencial de utilização na alimentação animal, na forma de silagem. Os ensaios que não apresentaram diferenças entre híbridos estão entre os de maior coeficiente de variação do trabalho. A precisão experimental mais baixa pode ter prejudicado a detecção de diferenças entre os genótipos.

Ciência Rural, v.35, n.3, mai-jun, 2005. 
Tabela 1 - Análise de variância conjunta e por local para a produtividade de matéria seca (t ha $\left.{ }^{-1}\right)$ e produtividade de leite $\left(\mathrm{kg}\right.$ ha $\left.{ }^{-1}\right)$ de híbridos de milho em sete locais da Região Sul, no ano agrícola de 2001/2002.

\begin{tabular}{|c|c|c|c|c|c|c|c|c|c|}
\hline Fontes de variação & GL & Conjunta & Cascavel & Chapecó & Ijuí & Lages & Ponta Grossa & Teutônia & Urussanga \\
\hline \multicolumn{10}{|c|}{ Produção de matéria seca } \\
\hline Bloco & 2 & $23,3 * *$ & $1,4^{\text {ns }}$ & $31,7 * *$ & $15,0^{*}$ & $36,9 * *$ & $3,4^{\text {ns }}$ & $1,5^{\mathrm{ns}}$ & $2,7 *$ \\
\hline Híbrido & 20 & $15,6^{* *}$ & $8,4^{* *}$ & $8,7^{\mathrm{ns}}$ & 2,7 & $16,4^{* *}$ & $12,5^{*}$ & $13,9 * *$ & $4,8^{* *}$ \\
\hline Local & 6 & $1117,0^{* *}$ & - & - & - & - & - & - & - \\
\hline Híbrido*local & 120 & $8,6^{* *}$ & - & - & - & - & - & - & - \\
\hline Erro & 292 & 3,0 & 1,8 & 5,7 & 2,9 & 2,3 & 1,2 & 3,7 & 0,7 \\
\hline$\overline{\mathrm{CV}}$ & & 13,2 & 7,0 & 20,6 & 19,6 & 10,9 & 5,9 & 19,1 & 8,7 \\
\hline Média geral & & 13,1 & 19,2 & 11,6 & 8,7 & 13,8 & 18,3 & 10,0 & 9,9 \\
\hline
\end{tabular}

\begin{tabular}{|c|c|c|c|c|c|c|c|c|c|}
\hline \multirow[b]{2}{*}{ Bloco } & \multicolumn{8}{|c|}{ Produção de leite } & \multirow[b]{2}{*}{$463797^{*}$} \\
\hline & 2 & $4371736^{* *}$ & $252602^{\mathrm{ns}}$ & $5401162 *$ & $3113083^{* *}$ & $7043782 * *$ & 785 945* & $267573^{\mathrm{ns}}$ & \\
\hline Híbrido & 20 & $10464895^{* *}$ & $4890140 * *$ & $2144261^{*}$ & $1000189^{\mathrm{ns}}$ & $4043197 * *$ & $3561499 * *$ & $3606863 * *$ & $1906552 *$ \\
\hline Local & 6 & 217672 952** & - & - & - & - & - & - & - \\
\hline Híbrido*local & 120 & $1781302 * *$ & - & - & - & - & - & - & - \\
\hline Erro & 292 & 568915 & 334604 & 1115103 & 584760 & 394070 & 234096 & 702476 & 140154 \\
\hline $\mathrm{CV}$ & & 13,0 & 6,8 & 20,6 & 19,9 & 10,3 & 6,0 & 18,9 & 8,5 \\
\hline Média geral & & 5779 & 8515 & 5114 & 3845 & 6100 & 8063 & 4439 & 4383 \\
\hline
\end{tabular}

$*$ = significativo a $5 \%, * *=$ significativo a $1 \%,{ }^{\text {ns }}=$ não significativo pelo teste $\mathrm{F}$

Embora existam poucos trabalhos sobre o assunto, têm sido detectadas diferenças entre genótipos de milho, tanto para a produção total de matéria seca como para caracteres que afetam a qualidade da silagem produzida (ANTONIALI et al., 2003; OLIVEIRA et al, 2003). Em ensaios realizados em Santa Catarina, desde o ano agrícola de 1996/97, as médias de produção de matéria seca variaram de 10,11 a 15,95t ha $^{-1}$ para Chapecó e de 13,14 a 15,67 h $^{-1}$ para Urussanga (LAJÚS et al., 1997, 1998 e 1999; DAL FARRA et al., 1999; MIRANDA et al., 2000; DUFLOTH et al., 2000). Para Lages, em 1999/2000, a média foi de 16,17t ha-1 (ZANATTA et al., 2000). As médias obtidas para estes locais no atual trabalho foram semelhantes às registradas na literatura.

Na comparação das médias dos híbridos pelo teste de Scott e Knott, foram formados, em Cascavel, dois grupos para produção de matéria seca de silagem, dos quais o grupo superior incluiu onze dos 21 híbridos (Tabela 2). No experimento de Lages, foram formados três grupos, sendo os híbridos TORK, AGN3100, SG6418, OC705, AGN3050, 97HT129 e DAS766 superiores. Em Ponta Grossa, foram formados quatro grupos, tendo-se destacado os híbridos AGN3180 e TRAKTOR. No experimento de Teutônia, doze híbridos permaneceram no grupo superior, dos dois formados. Em Urussanga, foram formados três grupos, destacando-se os híbridos AGN3180, OC705 e CD3121.

As médias dos híbridos para cada um dos caracteres de qualidade são apresentadas na Tabela 4 . O teor de proteína bruta variou de 7,0 a 8,2\% e o de fibra em detergente neutro de 52,6 a $57,1 \%$. A digestibilidade foi de 64,2 a $67,6 \%$. Devido ao alto custo das análises, estas foram realizadas para apenas uma amostra composta por local, não sendo possível realizar análises semelhantes aos demais caracteres.

Para a produtividade de leite, foram formados três grupos no ensaio de Cascavel, e os híbridos pertencentes ao grupo superior foram AGN3100, AGN3180, AG122, 97 HT129, AS3477, AG5011 e OC705 (Tabela 3). Em Lages, foram formados quatro grupos, com destaque para os híbridos AGN3100, OC705 e 97HT129. Em Ponta Grossa, foram formados cinco grupos e o melhor híbrido foi o AGN3180, seguido do OC705 e AGN3100. Em Teutônia, foram formados dois grupos, ficando onze híbridos no grupo superior. No experimento de Urussanga, foram formados quatro grupos, e destacaram-se os híbridos AGN3180 e OC705. Em Chapecó, embora tenha havido significância do 
Tabela 2 - Médias de produtividade de matéria seca (t ha ${ }^{-1}$ ) de híbridos de milho em sete locais da Região Sul no ano agrícola de $2001 / 2002$.

\begin{tabular}{|c|c|c|c|c|c|c|c|c|c|c|c|c|c|c|}
\hline Híbrido & Cascavel & & Chapecó & & Ijuí & & Lages & & Ponta Grossa & & Teutônia & & Urussanga & \\
\hline AGN3180 & 21,6 & $\mathrm{~b}^{1}$ & 11,3 & $\mathrm{a}$ & 9,0 & $\mathrm{a}$ & 13,2 & $\mathrm{~b}$ & 22,1 & $\mathrm{~d}$ & 14,0 & $\mathrm{~b}$ & 12,6 & $\mathrm{C}$ \\
\hline OC705 & 19,3 & $\mathrm{~b}$ & 14,5 & $\mathrm{a}$ & 10,3 & $\mathrm{a}$ & 16,5 & c & 19,7 & c & 10,2 & $\mathrm{~b}$ & 12,0 & C \\
\hline TRAKTOR & 18,4 & $\mathrm{a}$ & 11,3 & $\mathrm{a}$ & 8,8 & $\mathrm{a}$ & 12,9 & $\mathrm{~b}$ & 21,2 & $\mathrm{~d}$ & 13,6 & $\mathrm{~b}$ & 10,7 & $\mathrm{~b}$ \\
\hline AGN3100 & 21,7 & $\mathrm{~b}$ & 9,6 & $\mathrm{a}$ & 7,5 & $\mathrm{a}$ & 17,3 & $\mathrm{c}$ & 19,7 & $\mathrm{C}$ & 10,7 & b & 10,4 & $\mathrm{~b}$ \\
\hline P3041 & 19,6 & $\mathrm{~b}$ & 11,4 & $\mathrm{a}$ & 10,0 & $\mathrm{a}$ & 13,8 & $\mathrm{~b}$ & 19,3 & $\mathrm{C}$ & 11,8 & b & 9,2 & $\mathrm{a}$ \\
\hline AGN3050 & 17,8 & $\mathrm{a}$ & 12,9 & $\mathrm{a}$ & 7,8 & $\mathrm{a}$ & 16,0 & $\mathrm{C}$ & 20,1 & $\mathrm{C}$ & 9,9 & b & 9,8 & $\mathrm{a}$ \\
\hline HT14A & 18,1 & $\mathrm{a}$ & 12,7 & $\mathrm{a}$ & 8,5 & $\mathrm{a}$ & 12,5 & $\mathrm{~b}$ & 19,2 & $\mathrm{C}$ & 13,4 & b & 9,3 & $\mathrm{a}$ \\
\hline 97HT129 & 21,1 & $\mathrm{~b}$ & 11,9 & $\mathrm{a}$ & 9,5 & $\mathrm{a}$ & 15,9 & c & 16,5 & $\mathrm{~b}$ & 10,6 & b & 8,2 & $\mathrm{a}$ \\
\hline SG6418 & 20,2 & $\mathrm{~b}$ & 10,6 & $\mathrm{a}$ & 10,1 & $\mathrm{a}$ & 16,5 & c & 18,5 & c & 9,2 & $\mathrm{a}$ & 8,4 & $\mathrm{a}$ \\
\hline TORK & 18,3 & $\mathrm{a}$ & 11,3 & $\mathrm{a}$ & 8,4 & $\mathrm{a}$ & 18,3 & $\mathrm{C}$ & 18,5 & $\mathrm{C}$ & 7,8 & $\mathrm{a}$ & 10,5 & $\mathrm{~b}$ \\
\hline AG5011 & 20,0 & $\mathrm{~b}$ & 11,1 & $\mathrm{a}$ & 9,1 & $\mathrm{a}$ & 11,8 & $\mathrm{a}$ & 17,8 & $\mathrm{~b}$ & 11,2 & $\mathrm{~b}$ & 10,6 & $\mathrm{~b}$ \\
\hline DAS766 & 18,6 & $\mathrm{a}$ & 12,6 & $\mathrm{a}$ & 7,0 & $\mathrm{a}$ & 15,0 & c & 19,5 & c & 7,8 & $\mathrm{a}$ & 10,0 & $\mathrm{~b}$ \\
\hline AG122 & 21,5 & $\mathrm{~b}$ & 10,5 & $\mathrm{a}$ & 8,6 & $\mathrm{a}$ & 11,5 & $\mathrm{a}$ & 17,3 & $\mathrm{~b}$ & 10,2 & $\mathrm{~b}$ & 10,8 & $\mathrm{~b}$ \\
\hline AS1533 & 18,2 & $\mathrm{a}$ & 12,2 & $\mathrm{a}$ & 8,8 & $\mathrm{a}$ & 14,0 & $\mathrm{~b}$ & 18,2 & c & 8,5 & $\mathrm{a}$ & 9,4 & $\mathrm{a}$ \\
\hline DKB909 & 17,8 & $\mathrm{a}$ & 15,6 & $\mathrm{a}$ & 7,7 & $\mathrm{a}$ & 14,0 & $\mathrm{~b}$ & 19,1 & $\mathrm{C}$ & 7,1 & $\mathrm{a}$ & 7,8 & $\mathrm{a}$ \\
\hline CD3121 & 21,1 & $\mathrm{~b}$ & 10,5 & $\mathrm{a}$ & 9,7 & $\mathrm{a}$ & 10,6 & $\mathrm{a}$ & 17,1 & $\mathrm{~b}$ & 7,3 & $\mathrm{a}$ & 11,5 & c \\
\hline P3021 & 19,4 & $\mathrm{~b}$ & 13,4 & $\mathrm{a}$ & 8,6 & $\mathrm{a}$ & 11,4 & $\mathrm{a}$ & 17,1 & $\mathrm{~b}$ & 8,8 & $\mathrm{a}$ & 8,6 & $\mathrm{a}$ \\
\hline AS3477 & 20,8 & $\mathrm{~b}$ & 11,3 & $\mathrm{a}$ & 8,5 & $\mathrm{a}$ & 11,6 & $\mathrm{a}$ & 17,8 & $\mathrm{~b}$ & 7,5 & $\mathrm{a}$ & 9,0 & $\mathrm{a}$ \\
\hline BRS3150 & 16,5 & $\mathrm{a}$ & 11,0 & $\mathrm{a}$ & 8,1 & $\mathrm{a}$ & 14,3 & $\mathrm{~b}$ & 16,6 & $\mathrm{~b}$ & 7,6 & $\mathrm{a}$ & 9,3 & $\mathrm{a}$ \\
\hline CD304 & 16,1 & $\mathrm{a}$ & 10,3 & $\mathrm{a}$ & 9,4 & $\mathrm{a}$ & 9,6 & $\mathrm{a}$ & 16,1 & $\mathrm{~b}$ & 10,7 & b & 10,6 & $\mathrm{~b}$ \\
\hline НT40B & 17,4 & $\mathrm{a}$ & 7,5 & $\mathrm{a}$ & 7,0 & $\mathrm{a}$ & 13,5 & $\mathrm{~b}$ & 12,4 & $\mathrm{a}$ & 12,3 & b & 8,7 & $\mathrm{a}$ \\
\hline
\end{tabular}

${ }^{1}$ Médias de tratamento seguidas da mesma letra não diferem significativamente pelo teste de Scott-Knott a 5\% de probabilidade de erro.

Tabela 3 - Médias de produtividade de leite $\left(\mathrm{kg} \mathrm{ha}^{-1}\right)$ de híbridos de milho em sete locais da Região Sul no ano agrícola de 2001/2002.

\begin{tabular}{|c|c|c|c|c|c|c|c|c|c|c|c|c|c|c|}
\hline Híbrido & Cascavel & & Chapecó & & Ijuí & & Lages & & Ponta Grossa & & Teutônia & & Urussanga & \\
\hline AGN3180 & 10494 & $c^{1}$ & 5474 & $\mathrm{a}$ & 4392 & $\mathrm{a}$ & 6432 & C & 10735 & $\mathrm{e}$ & 6816 & $\mathrm{~b}$ & 6105 & $\mathrm{~d}$ \\
\hline OC705 & 9380 & $\mathrm{C}$ & 7027 & $\mathrm{a}$ & 4981 & $\mathrm{a}$ & 8003 & $\mathrm{~d}$ & 9563 & d & 4967 & $\mathrm{~b}$ & 5817 & $\mathrm{~d}$ \\
\hline AGN3100 & 10529 & $\mathrm{C}$ & 4679 & $\mathrm{a}$ & 3624 & $\mathrm{a}$ & 8389 & $\mathrm{~d}$ & 9569 & d & 5199 & $\mathrm{~b}$ & 5048 & C \\
\hline 97HT129 & 10252 & c & 5806 & $\mathrm{a}$ & 4599 & $\mathrm{a}$ & 7721 & $\mathrm{~d}$ & 8000 & $\mathrm{~b}$ & 5166 & $\mathrm{~b}$ & 3969 & $\mathrm{~b}$ \\
\hline AG5011 & 9715 & c & 5409 & $\mathrm{a}$ & 4421 & $\mathrm{a}$ & 5730 & $\mathrm{~b}$ & 8656 & c & 5455 & $\mathrm{~b}$ & 5154 & c \\
\hline AG122 & 10428 & $\mathrm{C}$ & 5121 & $\mathrm{a}$ & 4201 & $\mathrm{a}$ & 5578 & $\mathrm{~b}$ & 8429 & c & 4964 & $\mathrm{~b}$ & 5259 & C \\
\hline AS1533 & 8840 & $\mathrm{~b}$ & 5922 & $\mathrm{a}$ & 4273 & $\mathrm{a}$ & 6799 & $\mathrm{C}$ & 8870 & c & 4110 & $\mathrm{a}$ & 4570 & $\mathrm{~b}$ \\
\hline AS3477 & 10109 & $\mathrm{C}$ & 5499 & $\mathrm{a}$ & 4115 & $\mathrm{a}$ & 5639 & $\mathrm{~b}$ & 8650 & c & 3652 & $\mathrm{a}$ & 4370 & $\mathrm{~b}$ \\
\hline BRS3150 & 8046 & $\mathrm{~b}$ & 5371 & $\mathrm{a}$ & 3952 & $\mathrm{a}$ & 6949 & c & 8087 & $\mathrm{~b}$ & 3702 & $\mathrm{a}$ & 4543 & $\mathrm{~b}$ \\
\hline CD304 & 7821 & $\mathrm{~b}$ & 5011 & $\mathrm{a}$ & 4553 & $\mathrm{a}$ & 4652 & $\mathrm{a}$ & 7822 & $\mathrm{~b}$ & 5184 & $\mathrm{~b}$ & 5166 & c \\
\hline DKB909 & 7853 & $\mathrm{~b}$ & 6891 & $\mathrm{a}$ & 3406 & $\mathrm{a}$ & 6183 & $\mathrm{C}$ & 8447 & c & 3151 & $\mathrm{a}$ & 3426 & $\mathrm{a}$ \\
\hline НТ40В & 8453 & $\mathrm{~b}$ & 3649 & $\mathrm{a}$ & 3406 & $\mathrm{a}$ & 6583 & $\mathrm{C}$ & 6040 & $\mathrm{a}$ & 5974 & $\mathrm{~b}$ & 4229 & $\mathrm{~b}$ \\
\hline TRAKTOR & 7175 & $\mathrm{a}$ & 4394 & $\mathrm{a}$ & 3452 & $\mathrm{a}$ & 5010 & $\mathrm{a}$ & 8278 & c & 5285 & $\mathrm{~b}$ & 4168 & $\mathrm{~b}$ \\
\hline P3041 & 7653 & $\mathrm{a}$ & 4444 & $\mathrm{a}$ & 3904 & $\mathrm{a}$ & 5377 & $\mathrm{~b}$ & 7508 & $\mathrm{~b}$ & 4582 & $\mathrm{~b}$ & 3581 & $\mathrm{a}$ \\
\hline AGN3050 & 6960 & $\mathrm{a}$ & 5010 & $\mathrm{a}$ & 3044 & $\mathrm{a}$ & 6247 & c & 7836 & $\mathrm{~b}$ & 3850 & $\mathrm{a}$ & 3832 & $\mathrm{a}$ \\
\hline HT14A & 7038 & $\mathrm{a}$ & 4938 & $\mathrm{a}$ & 3327 & $\mathrm{a}$ & 4854 & $\mathrm{a}$ & 7482 & $\mathrm{~b}$ & 5218 & $\mathrm{~b}$ & 3624 & $\mathrm{a}$ \\
\hline SG6418 & 7868 & $\mathrm{~b}$ & 4137 & $\mathrm{a}$ & 3920 & $\mathrm{a}$ & 6436 & c & 7210 & b & 3584 & $\mathrm{a}$ & 3291 & $\mathrm{a}$ \\
\hline TORK & 7147 & $\mathrm{a}$ & 4395 & $\mathrm{a}$ & 3282 & $\mathrm{a}$ & 7113 & C & 7202 & $\mathrm{~b}$ & 3039 & $\mathrm{a}$ & 4107 & $\mathrm{~b}$ \\
\hline DAS766 & 7262 & $\mathrm{a}$ & 4919 & $\mathrm{a}$ & 2736 & $\mathrm{a}$ & 5865 & $\mathrm{~b}$ & 7584 & $\mathrm{~b}$ & 3045 & $\mathrm{a}$ & 3909 & $\mathrm{a}$ \\
\hline CD3121 & 8220 & $\mathrm{~b}$ & 4093 & $\mathrm{a}$ & 3792 & $\mathrm{a}$ & 4119 & $\mathrm{a}$ & 6671 & $\mathrm{a}$ & 2840 & $\mathrm{a}$ & 4498 & $\mathrm{~b}$ \\
\hline P3021 & 7574 & $\mathrm{a}$ & 5203 & $\mathrm{a}$ & 3371 & $\mathrm{a}$ & 4431 & $\mathrm{a}$ & 6678 & $\mathrm{a}$ & 3447 & $\mathrm{a}$ & 3372 & $\mathrm{a}$ \\
\hline
\end{tabular}

${ }^{1}$ Médias de tratamento seguidas da mesma letra não diferem significativamente pelo teste de Scott-Knott a 5\% de probabilidade de erro.

Ciência Rural, v.35, n.3, mai-jun, 2005. 
Tabela 4 - Valores médios de proteína bruta (PB), fibra em detergente neutro (FDN) e digestibilidade in vitro da matéria seca (DIVMS) de híbridos de milho na Região Sul do Brasil. Média de sete locais no ano agrícola de 2001/2002.

\begin{tabular}{lccc}
\hline Híbrido & PB (\%) & FDN (\%) & DIVMS (\%) \\
\hline AGN3180 & 7,6 & 55,4 & 64,9 \\
OC705 & 7,0 & 56,9 & 64,2 \\
AGN3100 & 7,7 & 55,6 & 65,2 \\
97HT129 & 7,7 & 55,0 & 65,8 \\
AG5011 & 7,5 & 55,4 & 65,6 \\
AG122 & 7,1 & 57,1 & 64,6 \\
AS1533 & 7,8 & 56,2 & 65,1 \\
AS3477 & 7,6 & 55,8 & 65,3 \\
BRS3150 & 7,2 & 55,7 & 64,9 \\
CD304 & 7,4 & 54,5 & 66,0 \\
DKB909 & 7,3 & 54,3 & 65,5 \\
HT40B & 8,2 & 53,0 & 67,0 \\
TRAKTOR & 7,9 & 53,6 & 66,2 \\
P3041 & 7,5 & 53,9 & 66,4 \\
AGN3050 & 7,5 & 52,6 & 66,7 \\
HT14A & 7,9 & 54,3 & 66,0 \\
SG6418 & 7,3 & 53,7 & 66,2 \\
TORK & 7,4 & 53,1 & 67,0 \\
DAS766 & 7,5 & 53,5 & 67,6 \\
CD3121 & 7,7 & 54,4 & 66,8 \\
P3021 & 7,4 & 53,5 & 66,8 \\
\hline
\end{tabular}

efeito de híbridos, estes permaneceram em um único grupo pelo teste de Scott e Knott. Apesar da interação genótipos x ambientes, os híbridos AGN 3180, OC705 e AGN3100 permaneceram no grupo superior em praticamente todos os locais, o que é uma indicação de bom desempenho para toda a região.

\section{CONCLUSÕES}

Existe variabilidade entre os híbridos indicados para cultivo na Região Sul do Brasil quanto ao potencial de utilização na forma de silagem. Entretanto, o desempenho é fortemente influenciado pela interação de genótipos com ambientes, indicando a necessidade de uma regionalização da recomendação de cultivo. Apesar da importância da interação, os híbridos AGN 3180, OC705 eAGN3100 apresentaram bom desempenho na maioria dos ambientes analisados.

\section{REFERÊNCIAS BIBLIOGRÁFICAS}

ALMEIDA FILHO, S.L. Avaliação de cultivares de milho (Zea mays L.) para silagem. Viçosa : UFV, 1996. 53p.

ANTONIALI, M. et al. Avaliação de cultivares de milho (Zea mays L.) para a produção de silagem: composição bromatológica. In : REUNIÃO DA SOCIEDADE BRASILEIRA DE ZOOTECNIA, 40., 2003, Santa Maria, RS. Anais... Santa Maria : SBZ, 2003. (CD-room).

BITENCOURT, D. et al. A importância da atividade leiteira na economia agropecuária do Rio Grande do Sul. In: BITENCOURT et al. (eds.). Sistemas de pecuária de leite: uma visão na região de Clima Temperado. Pelotas : Embrapa Clima Temperado, 2000. p.11-26.

CRUZ, C.D. Programa GENES, versão Windows. Viçosa : UFV, 2001. 672p.

DAL FARRA, L. et al. Competição de cultivares de milho para ensilagem no Litoral Sul Catarinense - Safra 98/99. In: REUNIÃO TÉCNICA CATARINENSE DE MILHO E FEIJÃO, 2., 1999, Lages SC. Resumos... Lages : UDESC/Epagri, 1999. p.114-118.

DUFLOTH, J.H. et al. Competição de cultivares de milho para ensilagem no Litoral Catarinense -Safra 19999/2000. In: REUNIÃO TÉCNICA ANUAL DO MILHO, 45; REUNIÃO TÉCNICA DO SORGO, 28., 2000, Pelotas RS. Anais... Pelotas : Embrapa Clima Temperado, 2000. p.73-80. (Embrapa Clima Temperado. Documentos, 70).

GOMES, J.F. et al. Produção e utilização de alimentos. In: BITENCOURT et al. (eds.). Sistemas de pecuária de leite: uma visão na região de Clima Temperado. Pelotas : Embrapa Clima Temperado, 2000. p.63-100.

GOMES, S.T. Situação atual e tendências da competitividade de sistemas de produção. In: VILELA, D. et al. (eds.). O agronegócio do leite e políticas públicas para o seu desenvolvimento sustentável. Juiz de Fora : Embrapa Gado de Leite, 2002. p.67-81.

LAJÚS, C.A. et al. Competição de cultivares de milho para ensilagem no Oeste de Santa Catarina. In: REUNIÃO TÉCNICA ANUAL DO MILHO, 42; REUNIÃO TÉCNICA DO SORGO, 25., 1997, Erechim RS. Anais... Erechim : Cooperativa Tritícola Erechim, 1998. p.63-69.

LAJÚS, C.A. et al. Competição de cultivares de milho para ensilagem no Oeste Catarinense - Safra 97/98. In: REUNIÃO TÉCNICA CATARINENSE DE MILHO E FEIJÃO, 1., 1998, Chapecó SC. Anais... Chapecó : Epagri, 1998. p.67-71.

LAJÚS, C.A. et al. Competição de cultivares de milho para ensilagem no Oeste Catarinense - Safra 98/99. In: REUNIÃO TÉCNICA CATARINENSE DE MILHO E FEIJÃO, 2., 1999, Lages SC. Resumos... Lages : UDESC/Epagri, 1999. p.109113.

MELO, W.M. C. et al. Avaliação de cultivares de milho para a produção de silagem na região de Lavras-MG. Ciência e Agrotecnologia, v.23, n.1, p.31-39, 1999.

MIRANDA, M. et al. Competição de cultivares de milho para ensilagem no Oeste Catarinense -Safra 19999/2000. In: REUNIÃO TÉCNICA ANUAL DO MILHO, 45; REUNIÃO TÉCNICA DO SORGO, 28., 2000, Pelotas RS. Anais... Pelotas : Embrapa Clima Temperado, 2000. p.56-63. (Embrapa Clima Temperado. Documentos, 70).

OLIVEIRA, J.S. Avaliação de cultivares de milho para silagem: resultados preliminares do ano agrícola 2000/2001. Juiz de Fora : Embrapa Gado de Leite, 2001. 40p. (Embrapa Gado de Leite. (Circular Técnica, 65).

OLIVEIRA, J.S. et al. Potencial de utilização de híbridos comerciais de milho para silagem na Região Sudeste do Brasil. 
Revista Brasileira de Milho e Sorgo, v.2, n.1, p.62-71, 2003.

RAMALHO, M.A.P. et al. Experimentação em genética e melhoramento de plantas. Lavras : UFLA, 2000. $326 p$.

SCOTT, A.J.; KNOTT, M. Acluster analysis method for grouping means in the analysis of variance. Biometrics, Raleigh, v.30, n.3, p.507-512, 1974.

STEEL, R.G.D.; TORRIE, J.H. Principles and procedures of statistics. 2.ed. New York: McGraw-Hill, 1980. 633 p.

UNDERSANDER, D.J. et al. Milk per acre spreadsheet for combining yield and quality into a single term. Journal of Production Agriculture, Madison, v.6, n.2, p.231-235, 1993.
VILLELA, T.E.A. Época de semeadura e de corte de plantas de milho para silagem. 2001. 86f. Dissertação (Mestrado em Fitotecnia) - Universidade Federal de Lavras.

YAMAGUCHI, L.C.T. et al. Eficiência em sistemas de produção de leite na Região Sul do Brasil. In: VILELA, D. et al. (eds. O agronegócio do leite e políticas públicas para o seu desenvolvimento sustentável. Juiz de Fora : Embrapa Gado de Leite, 2002. p.325-350.

ZANATTA, J.C. et al. Competição de cultivares de milho para ensilagem no Planalto Catarinense -Safra 19999/ 2000. In: REUNIÃO TÉCNICA ANUAL DO MILHO, 45.; REUNIÃO TÉCNICA DO SORGO, 28., 2000, Pelotas RS. Anais... Pelotas : Embrapa Clima Temperado, 2000. p.64-72. (Embrapa Clima Temperado. Documentos, 70). 